\title{
A prospective study on assessment of risk factors and impact of patient counselling in health-related quality of life of patients with coronary artery diseases
}

\author{
Neenu Babu, Shamna C., Sreelekshmi V. S., \\ Philip John Sebastian, Prasobh G. R., Nithin Manohar R.*
}

Department of Pharmacy Practice, Sreekrishna College of Pharmacy and Research Centre, Kerala, India

Received: 05 October 2020

Revised: 06 November 2020

Accepted: 07 November 2020

\section{*Correspondence:}

Dr. Nithin Manohar R.,

Email: ntnmanohar@yahoo.com

Copyright: (C) the author(s), publisher and licensee Medip Academy. This is an open-access article distributed under the terms of the Creative Commons Attribution Non-Commercial License, which permits unrestricted non-commercial use, distribution, and reproduction in any medium, provided the original work is properly cited.

\begin{abstract}
Background: Cardiovascular disease is the most frequent cause of morbidity and mortality throughout the world. The aim of the study was to determine assessment of risk factors and impact of patient counseling in health-related quality of life of the patient.

Method: This was a prospective observational study conducted in the department of cardiology. A suitably designed standard SF-36 questionnaire was given to all patients enrolled in the study before and after counseling. All information relevant to the study were collected in suitably designed proforma from case records and discussions conducted with the patients and bystanders during ward rounds. Proper counseling was given to patients and bystanders and the score was analyzed using SAS descriptive analysis.

Result: The most common risk factors encountered in the study are diabetes mellitus, hypertension, dyslipidemia, irregular exercise, smoking, alcoholism, obesity and family history. The health-related quality of life of the patients were assessed, a total of 67 patients QOL was improved after counseling and 27 patients with no improvement. We found that patient counseling was effective for majority of patients.

Conclusions: We can conclude that the role of clinical pharmacist has a significant role in improving the healthrelated quality of life of patients through proper counseling. And more than half of the patients have a modifiable risk factor which can be managed through lifestyle modifications.
\end{abstract}

Keywords: Coronary artery disease, Short form-36, Quality of life

\section{INTRODUCTION}

Coronary artery disease (CAD), sometimes described as coronary heart disease (CHD), or ischemic heart disease (IHD), is a condition in which the vascular supply to the heart is impeded by atheroma, thrombosis or spasm of coronary arteries $^{1}$ This may impair the supply of oxygenated blood to cardiac tissue sufficiently to cause myocardial ischemia which, if severe or prolonged, may cause the death of cardiac muscle cells. ${ }^{2}$ Depending on the degree of stenosis (narrowing) and plaque characteristics, patient may experience stable angina (angina pectoris) or remain asymptomatic until a plaque ruptures and thrombosis occurs, causing acute coronary syndrome $(\mathrm{ACS}){ }^{3}$

CAD has emerged as the dominant chronic disease in many parts of the world, and early in the $21^{\text {st }}$ century it is predicted to become the main cause of disability and death worldwide. The world health organization (WHO) has estimated that out more than 1 in 7 deaths in 2015 were caused by coronary artery disease. ${ }^{4}$ In 2000 , there 
were an estimated 29.8 million people with CAD in India, out of a total estimated population of 1.03 billion people or a nearly 3\% overall prevalence (Gupta, 2008, India Census, 2001). ${ }^{5} 20 \%$ of all deaths in Kerala are caused by CHD/CAD. The CAD rates in Kerala are higher than those of industrialized countries and 3-6 times higher than Japanese and rural Chinese. The life time risk of developing CAD after age 40 is $49 \%$ for men and $32 \%$ for women. ${ }^{6}$ With increasing age the differences in mortality rates between men and women decrease. ${ }^{7}$

Systematic large-scale studies of investigations on living populations have revealed a number of risk factors which are associated with increased risk of developing clinical atherosclerosis. Often, they are acting in combination rather than singly. These risk factors are divided into two groups. One is major risk factors consisting of age, gender, genetic factors, familial and racial factors (nonmodifiable risk factors) and hypertension, diabetes mellitus, dyslipidemia, smoking (modifiable risk factors or modified by lifestyle and or therapy). And the second one is emerging risk factors like obesity, environmental influences, hormonal imbalance, physical inactivity, stressful life, alcoholism, prothrombotic factors etc. ${ }^{8}$

The constitution of the WHO defines health as "A state of complete physical mental, and social well-being not merely the absence of disease." CAD is responsible for morbidity, mortality and loss of QOL. The treatment of CAD is expensive and can consume a major part of patient income as the patient may require treatment for a longer duration of time. The assessment of these patients HRQOL has been tackled by several authors using both disease specific and generic instrument such as the SF-36 questionnaire. Short form health survey (SF-36) is a set of generic, coherent, and easily administered quality-of life measures. These measures rely upon patient selfreporting and are now widely utilized by managed care organizations and by Medicare for routine monitoring and assessment of care outcomes in adult patients. ${ }^{9}$

The study focuses on the assessment of risk factors and the importance of patient counseling in health-related quality of life patients with coronary artery disease.

\section{METHODS}

A prospective observational study was conducted in patients from the department of cardiology in cosmopolitan hospital who were diagnosed with CAD during the study period after obtaining permission for collection of data from the hospital ethical committee. Study was conducted for a period of 6 months (December 2018 to May 2019). A total of 94 patients who satisfies the inclusion criteria were included in the study.

Inclusion criteria consists of patients with CAD who are willing to participate in the study. Patients between the age of 30 to 80 years with $\mathrm{CAD}$ and exclusion criteria includes, patients who are not willing to participate in the study, patients with age $<30$ years, pregnant women, psychiatric patients, bleeding disorders/thrombocytopenia

\section{Study procedure}

Written informed consents were obtained as per ICMR biomedical research guideline format from the patients of with CAD satisfying the inclusion and exclusion criteria. All relevant information regarding the study were collected from case records and direct interview with the patients. Data from patients were collected by using a suitably designed proforma. Additional demographic data of patient such as past medical history, family history, social history, personal history, residential location, presenting symptoms and prescriptions were obtained. The patients were then educated about the risk factors, disease, prevention and management. To assess the health-related quality of life (HRQoL) of patients with CAD, suitably designed SF-36 questionnaire has been used before and after the introduction of an information leaflet. The questionnaire includes multi-item scales to assess the eight dimensions of wellness; physical functioning, role limitations due to physical health problems, body pain, general health perceptions, social functioning, vitality, energy or fatigue and role limitations due to emotional problems. Each of the subscales is scored on a scale of 0-100, with high score indicates better HRQoL. A pilot was also conducted in a small population prior to the original study after obtaining the ethical clearance.

\section{Statistical analysis}

Frequencies and percentage were calculated as summary measures. Chi-square test for goodness of fit was used for testing significant proportional difference between classes, chi-square test for association was used for finding significant association between level of diagnosis and different risk factors. If self-count $<5$ then Fischer exact test was employed and a calculated $p$ value $<0.05$ is considered to be statistically significant. All analysis was done with the help of SPSS, version 22.

\section{RESULTS}

From the demographic profile, it was observed that among the 94 patients $67(71.3 \%)$ were males and 27 (28.7\%) were females. Thus, majority of patients are male. The age distribution of patients with CAD is represented in (Figure 1).

From (Table 1) it is observed that the highest number of patients were between the age group of 61-70 years (35 patients, $37.2 \%$ ) followed by the age group of 51-60 years (25 patients, 26.6\%), 71-80 years (23 patients, $24.5 \%), 41-50$ years (9 patients, $9.6 \%)$ and $30-40$ years $(2$ patients, $2.1 \%$ ). Thus, majority of patients were between the age group 61 to 70 . 


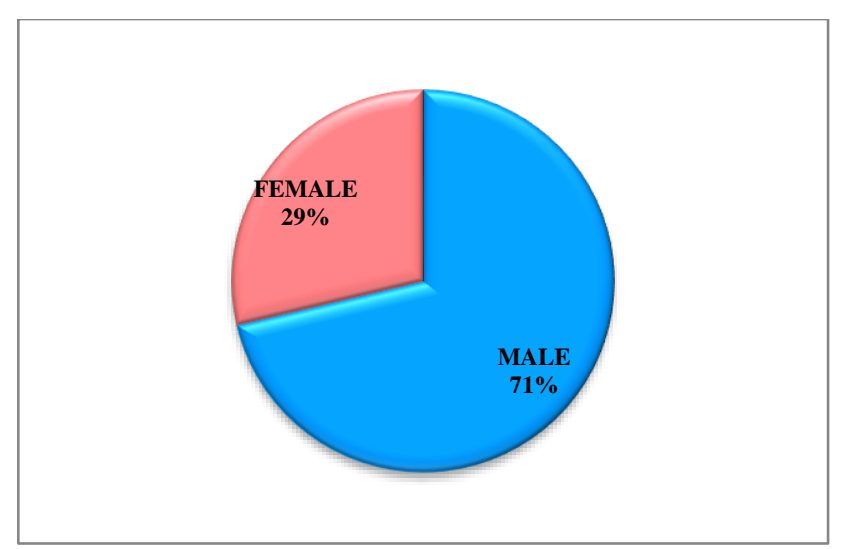

Figure 1: Diagrammatic representation of percentage distribution of patients based on gender.

Table 1: Frequency and percentage distribution of patients based on age.

\begin{tabular}{|lll|}
\hline Age (in year) & Frequency & Percentage $(\%)$ \\
\hline $\mathbf{3 0 - 4 0}$ & 2 & 2.1 \\
\hline $\mathbf{4 1 - 5 0}$ & 9 & 9.6 \\
\hline $\mathbf{5 1 - 6 0}$ & 25 & 26.6 \\
\hline $\mathbf{6 1 - 7 0}$ & 35 & 37.2 \\
\hline $\mathbf{7 1 - 8 0}$ & 23 & 24.5 \\
\hline
\end{tabular}

In our study a total of 69 patients have hypertension (73.4\%), 60 patients had dyslipidemia (63.8\%), 75 patients had diabetes mellitus $(79.8 \%), 42$ patients were smokers (44.7\%), 16 patients were alcoholic (17\%), 37 patients had family history of CAD (60.6\%) and 85 patients $(90.4 \%)$, overweight $(36.2 \%)$ were without regular exercise. The $\mathrm{p}$ value was significant for hypertension, diabetes mellitus and dyslipidemia that is $\mathrm{p}<0.05$. this is represented in the (Figure 2).

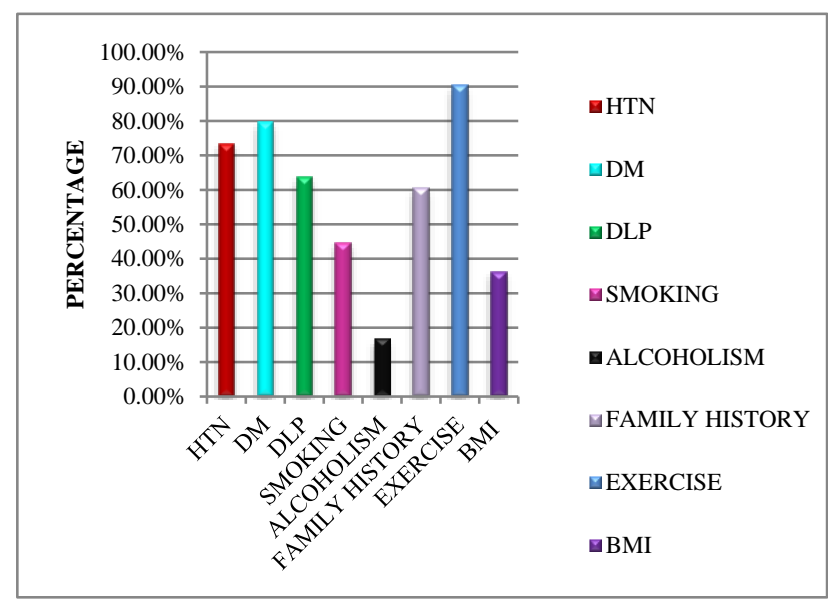

Figure 2: Diagrammatic representation of overall percentage distribution of risk factors associated with CAD.

From the (Table 2) it is observed that a significant majority $(67,71.3 \%)$ of patient's quality of life is improved after counseling but a total of 27 patients
(28.7\%) shows no improvement in their quality of life after counseling. The significance $(\mathrm{p}=0.000)$ of $\mathrm{p}$ value implies the positive impact of counseling.

Table 2: Percentage distribution of patients based on improvement in the quality of life of patients after counseling.

\begin{tabular}{|llll|}
\hline Category & Frequency & $\begin{array}{l}\text { Percentage } \\
(\%)\end{array}$ & $\begin{array}{l}\text { P } \\
\text { value }\end{array}$ \\
\hline $\begin{array}{l}\text { Patient with } \\
\text { improved QOL }\end{array}$ & 67 & 71.3 & \\
\hline $\begin{array}{l}\text { Patients } \\
\text { without } \\
\text { improved QOL }\end{array}$ & 27 & 28.7 & 0.000 \\
\hline
\end{tabular}

The descriptive statistics was obtained from the SAS programme. The present study assessed all the eight domains of QOL in the study subjects. Role limitations due to physical health was the significantly affected domain among all the eight domains of the QOL and an average score was found to be $8.21 \pm 11.83 \%$, before counselling. After counselling it seen that a significant improvement in all domains $(\mathrm{p}=0.001)$. The follow up period was between one and half months of first visit (Figure 3).

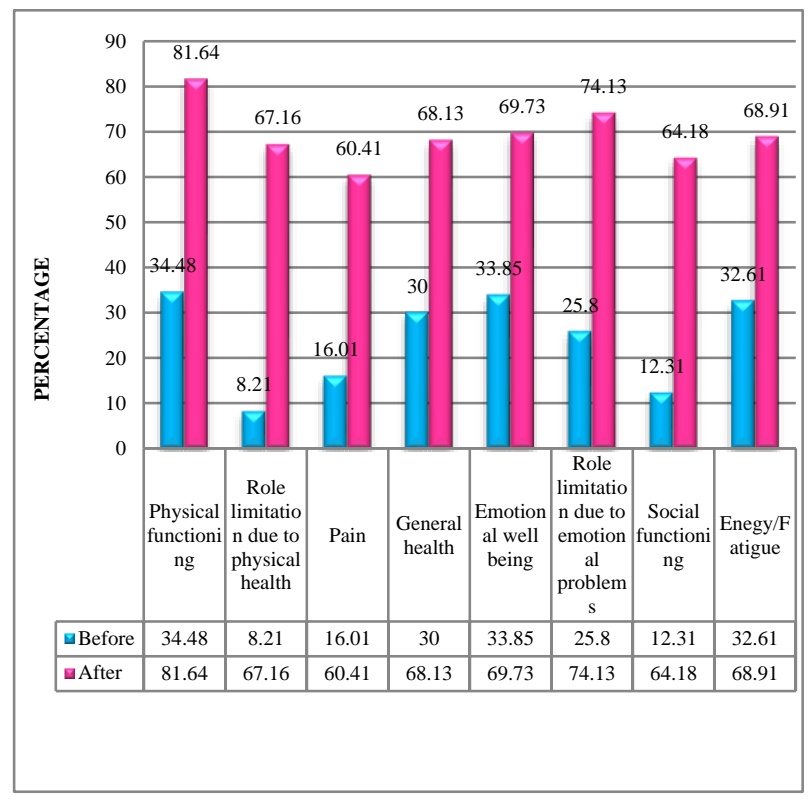

Figure 3: Percentage distribution of 8 domains of QOL-questionnaire before and after counseling.

The present study had revealed that there is significant correlation between physical health, mental health and coronary artery disease. Higher scores in each domain implies good quality of life. Thus, we can conclude that patient counselling plays a significant role in the healthrelated quality of life of patients. Hence it is being showed that, even though the mental and physical health is affected by the disease, effective counselling on diet 
and lifestyle changes can improve the patient health related quality of life.

In our study 67 patients showed improved quality of life after receiving the counselling and 27 patients without improvement in the QOL. The patients with no improvement in QOL were mostly geriatric patients (above 70).

From our study it is showed that there is a need for proper counselling on diet and life style changes to improve the patient health related quality of life.

\section{DISCUSSION}

In the present study the results indicated that most of the patients belong to the age group of $61-70$ (37.2\%) and $71-80(24.5 \%)$ due to the occurrence of comorbidities and the least occurrence was found in the age group of 30-40 $(2.1 \%)$ where the comorbidities are very less which is comparable with the study by Lian and Zachariah et al which shows that majority of patients were more than 60 years (38.6\%) and 51-60 year age group (39.07\%) respectively. The gender wise distribution of patients with CAD shows that among the 94 patients $67(71.3 \%)$ were males and $27(28.7 \%)$ were females. ${ }^{10,11}$

In the present study 69 patients have hypertension (73.4\%), 60 patients had dyslipidemia (63.8\%), 75 patients had diabetes mellitus (79.8), 42 patients were smokers (44.7), 16 patients were alcoholic (17\%), 37 patients had family history of CAD (39.4) and 85 patients were without regular exercise. In the present study the major risk factors include hypertension, diabetes mellitus, dyslipidemia was found to be the major risk factors for coronary artery disease. Zengin et al studied the risk factors of CAD in the secondary prevention and the major risk factors include diabetes mellitus, hypertension and smoking. ${ }^{12}$ In the study conducted by Mukhopadhyay et al hypertension, diabetes mellitus and hyperuricemia were found to be independent risk factors for coronary slow flow. ${ }^{13}$

Gender, close personal relationship, length of education, physical activity, vegetable and alcohol consumption, LDL-cholesterol, duration of coronary heart disease without previous percutaneous coronary intervention were found to be the predictors of adherence in a study conducted by the Parsa et al. ${ }^{14}$ A study was conducted by Chauhan et al, to assess perception and behavior in patients with coronary heart disease about the risk factors and lifestyle. The major risk factors were found to be hypertension, obesity, cholesterol, diabetes mellitus, tobacco, alcohol, family history and sedentary life style were found to be the major risk factors for coronary heart disease. $^{15}$

Shah et al studied type 2 diabetes and incidence of cardiovascular diseases. ${ }^{16}$ Heart failure and peripheral arterial disease are the most common initial manifestations of cardiovascular disease in type 2 diabetes mellitus. In our study, a total of 75 patients had diabetes mellitus $(79.8 \%)$. Dodani et al conducted a study on the presence of coronary artery disease in diabetic and non-diabetic South Asian immigrants. The susceptibility to diabetes among South Asian immigrants promotes an adverse CAD risk. ${ }^{17}$

In this study HRQoL was assessed using SF 36 questionnaire. There is a significant improvement in the quality of life of patients after the counseling. A total of $67(71.3 \%)$ patients have improved their quality of life and $27(28.7 \%)$ patients showed no improvement in quality of life after the counseling. Duenas et al assessed the heath related quality of life in coronary patients using SF-36 questionnaire. Several variables related to patient's clinical evolution and history of disease have been shown to be related to HRQoL, with worse results among women, subjects with previous history of CHD, and those with another co-morbidity. ${ }^{18}$

Morys et al assessed the quality of life in patients with coronary heart disease after myocardial infarction and with ischemic heart failure. ${ }^{19}$ In patients after MI and with stable CAD anxiety can be reduced by cognitive behavioral therapy while patients with heart failure require long term support therapy to reduce the risk of depressive symptoms. ${ }^{20}$

The limitations of our study include short duration, small sample size and also more follow ups are to be done to assess the health-related quality of life of patients undergoing various methods treatment like percutaneous coronary intervention, coronary artery bypass graft and medical management.

\section{CONCLUSION}

Pharmacists are in an ideal position to provide patient education and optimize patient care. The health-related quality of life of patients with coronary artery disease was assessed using SF-36 questionnaire before and after counseling. There is a significant improvement in the quality of life of patients $(71.3 \%)$ through proper patient education. The major risk factors associated with the study include diabetes mellitus, hypertension, dyslipidemia. Other conventional risk factors like smoking, alcoholism, family history, exercise, body mass index etc. were also found to have role. Understanding about the various aspects of disease like signs and symptoms, complications and the need for drug therapy and improved medication compliance yields better therapeutic outcomes.

\section{ACKNOWLEDGEMENTS}

Authors would like to thank Dr. Pradeep P., senior consultant interventional cardiologist, department of cardiology, cosmopolitan hospitals, who help us in 
completing the research successfully. Also thanking RAND organization for allow to use SF-36 questionnaire.

Funding: No funding sources

Conflict of interest: None declared

Ethical approval: The study was approved by the Institutional Ethics Committee

\section{REFERENCES}

1. Fausto. The Heart. In: Robbins, Cotran Kumar. Robbins and Cotran pathological Basis of Disease. $5^{\text {th }}$ edition. Philadelphia. Saunders International edition. 2005:524-8.

2. Mc Robbie D. Coronary heart disease. In: Roger Walker, eds. Clinical Pharmacy and Therapeutics, $5^{\text {th }}$ edition. London, Elsevier. 2012;312-5.

3. O'brien C. Cardiovascular drugs. In: Brunton LB, Lazo JS, Parker KL, eds. Goodman and Gillmans textbook for therapeutics. $11^{\text {th }}$ edition. Newyork, Mc Grawhill. 2005;502-19.

4. Bonow RO. Coronary artery diseases. In: Ziper DP, Libby P, Bonow RO, Braunwald E. Braunwald's Heart Disease-A Text Book of Cardiovascular Medicine. $7^{\text {th }}$ edition. Philadelphia. Elsevier. 2004;01-10.

5. Ferro A. Ischemic heart disease. In: Ritter JM, Lewus LD, Mant TGK, ferro A, eds. A textbook of clinical pharmacology and therapeutics. $5^{\text {th }}$ edition. Great Britian. Hodder education. 2008;196-210.

6. Yee GC. The cardiovascular system. In: Dipiro JT, Talbert RL, Yee GC, Matzke GR, Wells BG, Posey LM. Pharmacotherapy: A Pathophysiologic approach. $6^{\text {th }}$ edition. New York. McGraw-Hill medical publishing division. 2005;292-93.

7. Fuster V. Atherosceloris. In: Alexander RW, Rourke RAO, Roberts R, King SB, Nash IS, Drystowsky EN. Hurt's: The Heart. $2^{\text {nd }}$ ed. Mc Graw hill. Medical publishing division US. 2285.

8. Damjanov I. The Heart. In: Harsh Mohan. Text Book of Pathology, $7^{\text {th }}$ ed. New Delhi, Jaypee brothers' medical publishers. 2015;393-95.

9. Kumar L, Prakash A, Gupta SK. Assessment of economic burden and Quality of life in stable coronary artery disease patients. IJMS. 2019;10:26-9.

10. Lian CW, Yein LP, Yaman K, Wahab RA. A Preliminary Study on the Prevalence of Cardiovascular Disease Risk Factors in Selected Rural Communities in Samarahan and Kuching Division, Sarawak, Malaysia. Malaysian J Med Sci. 2011;18(2):59-66.
11. Zachariah TG, Subramanyam K, Pooja M, Vinayak J. Kempaller. Drug utilization study in ischemic heart disease in a tertiary care hospital, Mangalore, India. Int J Bio Clin Pract. 2017;6(7):1799-1805.

12. Zengin E, Bickel C, Schnabel RB. Risk factors of Coronary Artery Disease in secondary preventionResults from the Atherogene- study. Plos one. 2015;10(7):e0131434.

13. Mukhopadhyay S, Kumar M, Yusuf J, Gupta VK, Tyagi S. Risk factors and angiographic profile of coronary slow flow (CSF) phenomenon in North Indian population: An observational study. IHJ. 2018;70:405-9.

14. Parsa A, Sadeghi M, Roghahi F, Golshahi J, Khani A, Yazdekhasti $S$ et al. Effects of Changes in Myocardial Dysfunction on Quality of Life in Patients Undergoing Coronary Angioplasty After Cardiac Rehabilitation. Iranian Heart J. 2018;19(1):52-60.

15. Chauhan PA, Atul Trivedi. Study of prescription and behavior in patients with coronary heart disease about risk factors and life style modification in a tertiary care hospital, Bhavnagar. Int $\mathrm{j}$ comm med public health. 2019;6(4):1549-53.

16. Shah AD, Langenberg C, Rapsomaniki E, Denaxas S, Pujades MR, Gale CP, Deanfield J et al. Type 2 diabetes and incidence of cardiovascular diseases: a cohort study in 1.9 million people. Lancet Diabetes Endocrinol. 2015;3:105-13.

17. Dodani S, Sharma GK. Presence of coronary artery disease in diabetic and non-diabetic South Asian immigrants. IHJ. 2018;70:50-5.

18. Duenas M, Salazar A, Ojeda B, Failde I. Health Related Quality of Life in Coronary Patients. Preventive Medicine Public Health Dpt. University of Cadiz, Spain. 2012.

19. Morys JM, Pachalsk M, Bellvone J, Gruchala M. Quality of life in patients with coronary heart disease after Myocardal infarction and with Ischemic heart failure. Arch Med Sci. 2014;12(2): 326-33.

20. Zhang J-P, Pozuelo L, Brennan DM, Hoar B, Hoogwerf BJ. Association of SF-36 with Coronary Artery Disease, Risk factors and mortality: A PreCIS Study. Prev Cardiol. 2010;13:122-9.

Cite this article as: Babu N, Shamna C, Sreelekshmi VS, Sebastian PJ, Prasobh GR, Manohar NR. A prospective study on assessment of risk factors and impact of patient counselling in health-related quality of life of patients with coronary artery diseases. Int $\mathbf{J}$ Basic Clin Pharmacol 2020;9:1866-70. 